\title{
Comparative Effect of Casein and Soybean Protein Isolate on Body Fat Accumulation in Adult Rats
}

\author{
Sumie Shinjo, ${ }^{1}$ Liu Asato, ${ }^{1}$ Sayuri Arakaki, ${ }^{1}$ \\ Takeichi KInA, ${ }^{1}$ Tomoo KoHrin, ${ }^{2}$ \\ Masahiro MoRI, ${ }^{2}$ and Shigeru YAMAMOTO ${ }^{1}$ \\ ${ }^{1}$ Research Center of Comprehensive Medicine, Faculty of Medicine, \\ University of the Ryukyus, Okinawa 903-01, Japan \\ ${ }^{2}$ Department of Domestic Science, Kinran Junior College, \\ Suita, Osaka 565, Japan
}

(Received December 18, 1991)

\begin{abstract}
Summary The effect of dietary protein on the body fat accumulation was studied in rats. Adult rats weighing about $300 \mathrm{~g}$ were fed $21 \%$ protein (casein or soybean protein isolate) and $5 \%$ oil diets by pairfeeding for 65 days in Experiment 1. In Experiment 2, only protein and oil contents were changed, 25 and 10\%, respectively. Final body weights of the two dietary groups were similar in both experiments, especially in Experiment 2. Total body fat was slightly lower in the soybean protein diet group than in the casein diet group in Experiment 2, only when it was expressed as the percentage against body weight. However, intraabdominal fat was significantly lower in the soybean protein diet groups than in the casein diet groups in both experiments. Serum lipid levels were greatly lower in the soybean protein diet group than in the casein diet group in Experiment 2 (the data were not available in Experiment 1). The results suggest that dietary soybean protein has the effect to lower the intra-abdominal fat accumulation as compared with casein.

Key Words soybean protein isolate, casein, plasma lipids, body fat, intra-abdominal fat
\end{abstract}

The effects of dietary soybean protein on lowering the serum total-cholesterol and triglyceride levels have been observed in animals and men, usually by the comparison with casein (1-4). Iritani et al. (5) reported marked decrease of hepatic lipogenic enzymes by soybean protein. Saito (6) also reported high energy expenditure by brown adipose tissue in rats fed the soybean protein diet. Although these results suggest the reduction of body fat accumulation by soybean protein, there has been no study except one done by Inoue et al. (7). They did not observe the effect of soybean protein on lowering the fat accumulation in rats. However, such a result may be driven by the protein chosen as a representative of animal 
protein for the comparison. They used lactalbumin, but our recent studies (unpublished) showed that lactalbumin had rather the effects of lowering the serum cholesterol and triglycerides, which was similar to the effect of soybean protein.

Dietary protein level is also an important factor for the lipid metabolism. The difference in the growth of rats affects the serum lipid levels greatly $(8)$, indicating that the comparison of proteins should be done when the growth of animals is similar. The growth of rats is lower by soybean protein diet than by casein diet at the dietary protein level less than $20 \%(9,10)$. Therefore we should use the diet in which protein level is higher than $20 \%$. Furthermore, considering the effect of growth on lipid metabolism, adult rats may be preferable to young ones, because growth of the former is less than that of the latter.

We used two different diets. They were the diet of $21 \%$ protein and $5 \%$ oil (Experiment 1) and the diet of 25\% protein and 10\% oil (Experiment 2). There were three reasons for the choice of the diets. The first was that we could not observe clear difference of body fat accumulation in Experiment 1. The second was that by the higher dietary oil level, greater body fat accumulation could be expected (11). The third was not based on the scientific data, but on the expectation that the higher protein level would result in greater body fat accumulation.

\section{MATERIALS AND METHODS}

Animals and diets. Male Wistar strain rats (Ryukyu Bioteck, Okinawa) weighing about $300 \mathrm{~g}$ were used. Fourteen of them were sacrificed and taken as an initial control group. The others were divided into four groups consisting of 7 rats

Table 1. Composition of experimental diets.

$(\mathrm{g} \%)$

\begin{tabular}{lccccc}
\hline & \multicolumn{2}{c}{ Experiment 1} & & \multicolumn{2}{c}{ Experiment 2 } \\
\cline { 2 - 3 } \cline { 5 - 6 } & $21 \%$ Casein & $21 \%$ SPI & & $25 \%$ Casein & 25\% SPI \\
\hline Casein $^{1)}$ & 25 & - & & 30 & - \\
SPI $^{2)}$ & - & 25 & & - & 30 \\
$\alpha$-Corn starch $^{3)}$ & 42 & 42 & & 34 & 34 \\
Sucrose $^{4)}$ & 20 & 20 & & 17 & 17 \\
Soybean oil $^{5)}$ & 5 & 5 & & 10 & 10 \\
Vitamin mixture $^{6)}$ & 1 & 1 & & 2 & 2 \\
Salt mixture $^{6)}$ & 5 & 5 & & 5 & 5 \\
Cellulose $^{3)}$ & 2 & 2 & & 2 & 2 \\
Energy (kcal/100g) $^{n}$ & 393 & 393 & & 414 & 414 \\
\hline
\end{tabular}

1) Crude protein was $84.3 \%$. Obtained from Oriental Yeast Co., Ltd., Tokyo, Japan.

2) Crude protein was $84.4 \%$ (Fujipro R). Donated by Fuji Oil Co., Osaka, Japan.

${ }^{3)}$ Obtained from Oriental Yeast Co., Ltd., Tokyo, Japan. ${ }^{4)}$ Granular sugar was used.

${ }^{5)}$ Donated by Fuji Oil Co., Osaka, Japan. ${ }^{6)}$ Oriental Mixture. Obtained from

Oriental Yeast Co., Ltd., Tokyo, Japan. 
each and fed the experimental diets (Table 1). The first two groups were fed $21 \%$ casein and soybean protein isolate (SPI) diet, respectively. SPI commercialized as Fujipro-R (Fuji Oil Co., Osaka, Japan) was used. Each diet contained 5\% oil (Experiment 1). The last two groups were fed 25\% casein and SPI diet, respectively, and each diet contained 10\% oil (Experiment 2). The rats were maintained by pair-feeding for 65 days. Rats were kept in individual cages in an airconditioned room of $25 \pm 2{ }^{\circ} \mathrm{C}$ and of $70 \%$ humidity. Diets were prepared daily and water was given ad libitum from tap water with an automatically supplying system. Food intake was measured daily and body weight weekly.

Determination of body composition. The rats, which were fed for 65 days on the experimental diets, were sacrificed after overnight fast. The rats were anesthetized with sodium pentobarbital and blood was withdrawn by heart puncture into syringe. Intra-abdominal fat (12) which consists of abdominal fat pad and fatty portions surrounding intestines and testes, was removed and weighed. The carcass including the intra-abdominal fat was stored at $-35^{\circ} \mathrm{C}$ until analysis. The carcass was freeze-dried in a vacuum and then homogenized using a mixer. Amount of total body protein and fat was determined by Kjeldahl method (13) and ether extraction by Soxhlet apparatus (14), respectively.

Determination of plasma lipids. Plasma was separated by centrifugation (3,000 rpm, $15 \mathrm{~min})$ and stored at $-35^{\circ} \mathrm{C}$ until analysis. Plasma total cholesterol was determined by the COD-p-chlorophenol colorization method (15), HDLcholesterol by the heparin-manganese precipitation method (16) and triglycerides by GPO-p-chlorophenol colorization method (17). For the determination the biochemical analyzing kits (Wako Pure Chemical Industries, Osaka) were used.

Statistics. Difference of statistical significance was analyzed by Student's $t$-test.

\section{RESULTS}

Table 2 shows the values of the food intake, body weight, body and tail length, body protein, body and intra-abdominal fat and plasma lipids of the experimental rats in 65 days on the diets. In Experiment 1, the results were similar except the intra-abdominal fat weight and its percentage against body weight between the casein and SPI diet group. In Experiment 2, we increased protein and oil contents to 25 and $10 \%$, respectively. The average food intakes per day were similar in both groups, i.e., $65 \mathrm{kcal}$. Increment of body weight was very similar, being $110 \mathrm{~g}$ in casein group and $109 \mathrm{~g}$ in SPI group. Body and tail length were similar, showing that body figures were similar in both groups. Comparing the body compositions between both groups, the weight of body fat expressed as the percentage of body weight was significantly higher $(p<0.05)$ in the casein group than in the SPI group in Experiment 2. The intra-abdominal fat content was significantly higher in the casein groups in both experiments $(p<0.05)$.

Plasma lipid values were shown only for the samples of Experiment 2, because 


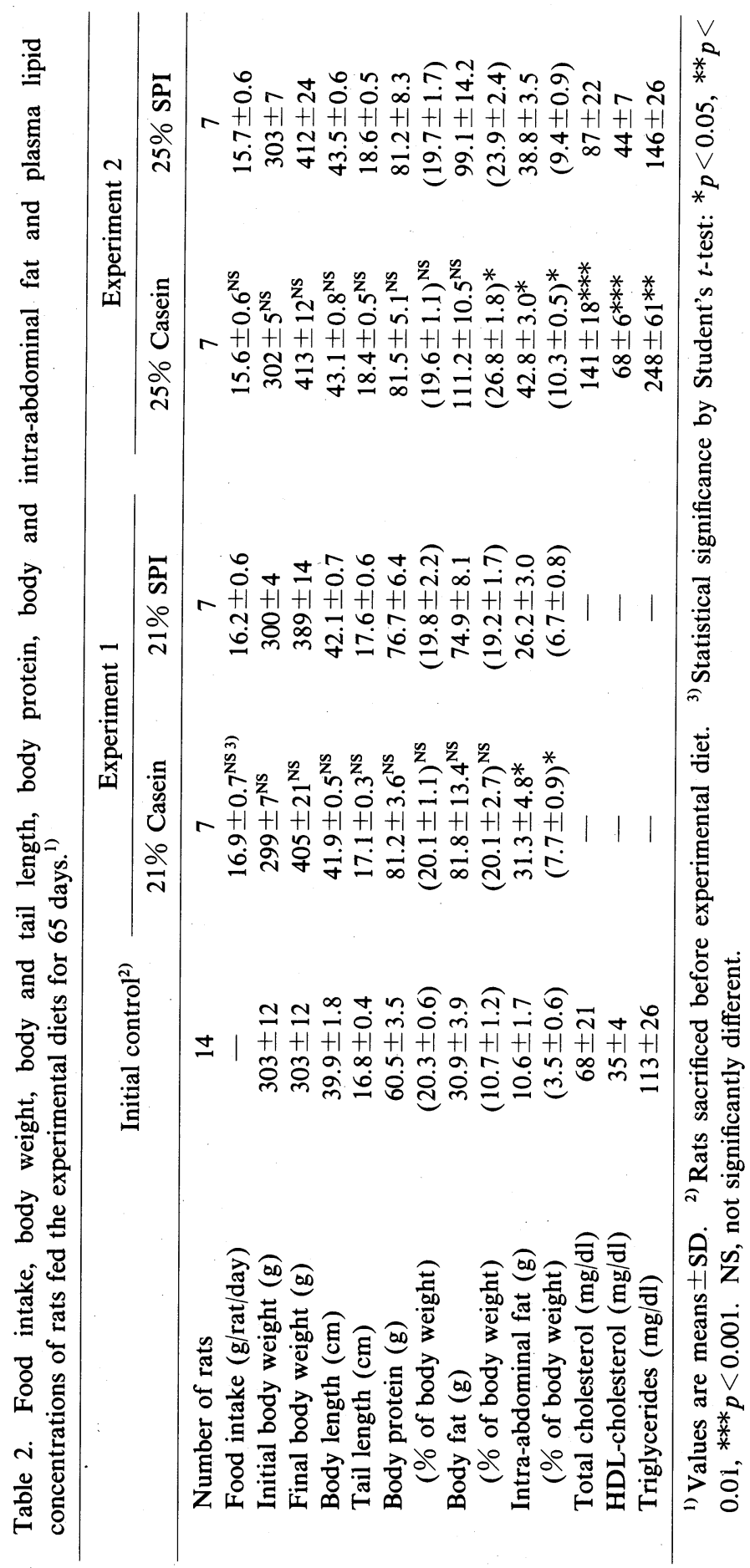


they were erroneously treated in Experiment 1 . The values were generally about two times higher in the casein group than in the initial control group. But they were slightly higher in the SPI group as compared to those of the initial control group. Total cholesterol, HDL-cholesterol and triglycerides of the casein group were significantly higher than those of the SPI group with the level of $p<0.001, p<0.001$ and $p<0.01$, respectively.

\section{DISCUSSION}

In Experiment 1, we used 21\% protein (casein and SPI) and 5\% oil diets. In Experiment 2, we increased both components to 25 and 10\%, respectively. There was no significant difference in the weight of body fat between the two dietary groups in either experiments but the weight of body fat expressed as percentage against body weight was lower in the SPI group than in the casein group in Experiment $2(p<0.05)$. However, the body fat difference was not evident and further studies are necessary to determine the different effect of the proteins on whole body fat.

Concerning the fat accumulation, the results on intra-abdominal fat were significant and need further evaluation. The intra-abdominal fat accumulation observed was lower in the SPI group than in the casein group in both experiments. The intra-abdominal fat accumulation was $31.3 \mathrm{~g}$ in the casein group and $26.2 \mathrm{~g}$ in the SPI group in Experiment 1, and 42.8 and $38.8 \mathrm{~g}$, respectively, in Experiment 2. The difference was about 5 or $4 \mathrm{~g}$. This was obtained from a small localized portion and was more than $10 \%$ of the intra-abdominal fat, indicating the significance of the difference. Fujioka et al. (12) observed that the intra-abdominal fat has a greater effect on lipid and glucose metabolism than does the subcutaneous fat in humans. For obesity, they classified abdominal and subcutaneous types. There are more diabetic (mellitus) and hyperlipidemic patients in the former type obesity than in the latter type. As for the mechanism, they estimate that the metabolism of intra-abdominal fat is more active than subcutaneous fat and also that the fat goes directly into liver and elevates the serum lipids. Although our experiments were observed in rats, the results were similar. The serum total- and HDL-cholesterol and triglycerides were much lower in the SPI group than in the casein group in Experiment 2 (the data were not available in Experiment 1).

Our observations that the SPI diet decreased both the intra-abdominal fat accumulation and plasma lipids would be supported by the data of other researchers; Iritani et al. (5) reported marked decrease of a series of enzymes concerning fatty acid synthesis in rat liver when rat was fed vegetable proteins (e.g., gluten, soybean protein) rather than animal proteins (e.g., casein, fish protein). Saito (6) reported a higher thermogenesis in rat brown adipose tissue when rat was maintained on a soybean protein hydrolyzate diet rather than on a well-balanced amino acid mixture diet. Many other reseachers also (1-4) observed lower serum lipids by soybean protein than by casein. 
In the present two experiments, we could show an effect of soybean protein on the reduction of body fat, especially intra-abdominal fat, by the comparison with casein; however, further experiments are necessary for the conclusion.

\section{REFERENCES}

1) Carroll, K. K., Huff, M. W., and Roberts, D. C. K. (1979): Vegetable protein and lipid metabolism, in Soy Protein and Human Nutrition, ed. by Wilcke, H. L., Hopkins, D. T., and Waggle, D. H., Academic Press, New York, pp. 261-280.

2) Kritchevsky, D. (1979): Vegetable protein and atherosclerosis. J. Am. Oil Chem. Soc., 56, 135-140.

3) Nagata, Y., Ishiwaki, N., and Sugano, M. (1982): Studies on the mechanism of antihypercholesterolemic action of soy protein and soy protein-type amino acid mixture in relation to casein counterparts in rats. J. Nutr., 112, 1614-1625.

4) Mizukami, T., Ito, A., Utsunomiya, K., Nishino, A., and Horikawa, R. (1988): Effects of soy protein isolate, casein, and their mixtures on the lipid levels in rat plasma and liver. Kaseigaku Kenkyu (Res. J. Living Sci.), 34, 98-106.

5) Iritani, N., Nagashima, K., Fukuda, H., Katsurada, A., and Tanaka, T. (1986): Effects of dietary protein on lipogenic enzymes in rat liver. J. Nutr., 116, 190-197.

6) Saito, M. (1989): Availability of soy protein peptides for total enteral nutrition. Nutr. Sci. Soy Protein, Jpn. (in Japanese), 10, 81-83.

7) Inoue, G., Kishi, K., Wang, M-F., and Watanabe, H. (1982): Effect of soy protein on carcass fat content in growing rats. Nutr. Sci. Soy Protein, Jpn. (in Japanese), 3, 7176.

8) Yu, B. P., Wong, G., Lee, H. C., Bertrand, H., and Masoro, E. J. (1984): Age changes in hepatic metabolic characteristics and their modulation by dietary manipulation. Mech. Age. Dev., 24, 67-84.

9) Inoue, G., Kishi, K., and Yagi, I. (1981): Nutritive value of soy protein isolate determined by slope ratio assay in growing rats. Nutr. Sci. Soy Protein, Jpn. (in Japanese), 2, 62-66.

10) Takahashi, T., Muramatsu, S., and Shibahara, Y. (1981): Comparison of nutritive values between soy protein isolate and other soy proteins. Nutr. Sci. Soy Protein, Jpn. (in Japanese), 2, 52-57.

11) Mickelsen, O., Takahashi, S., and Craig, C. (1955): Production of obesity in rats by feeding high-fat diets. J. Nutr., 57, 541-554.

12) Fujioka, S., Matsuzawa, Y., Tokunaga, K., and Tarui, S. (1987): Contribution of intra-abdominal fat accumulation to the impairment of glucose and lipid metabolism in human obesity. Metabolism, 36, 54-59.

13) Oser, B. L. (1965): Total nitrogen, in Hawk's Physiological Chemistry, ed. by Oser, B. L., McGraw-Hill, New York, pp. 1214-1215.

14) Pearson, D. (1976): The chemical analysis of foods, 7th ed. Churchill Livingstone, Edinburgh, London and New York, p. 207.

15) Richmond, W. (1973): Preparation and properties of a cholesterol oxidase from Nocardia sp. and its application to the enzymatic assay of total cholesterol in serum. Clin. Chem., 19, 1350-1356.

16) Naito, S. (1975): Standardization in plasma lipid and lipoprotein measurements, in 
America. Igaku no Ayumi (in Japanese), 94, 359-362.

17) Fukui, I., Sone, A., Kushiro, H., Masaki, K., and Takahata, J. (1973): Triglycerides. Nihon Rinsho (Jpn. J. Clin. Med.), 31, 1335-1349. 